\title{
Microbially Enhanced Oil Recovery by Alkylbenzene-Oxidizing Nitrate-Reducing Bacteria
}

\author{
Navreet Suri ${ }^{1 *}$, Fatma Gassara ${ }^{1,2}$, Paul Stanislav ${ }^{1}$ and Gerrit Voordouw ${ }^{1}$ \\ ${ }^{1}$ Petroleum Microbiology Research Group, Department of Biological Sciences, University of Calgary, Calgary, AB, Canada, \\ ${ }^{2}$ Biopterre, Sainte-Anne-de-la-Pocatière, QC, Canada
}

OPEN ACCESS

Edited by:

Terry C. Hazen

The University of Tennessee,

Knoxville, United States

Reviewed by:

Romy Chakraborty,

Lawrence Berkeley National

Laboratory, United States

Wei Li,

East China University of Science and Technology, China

William T. Stringfellow,

University of the Pacific, United States

*Correspondence:

Navreet Suri

nksuri@ucalgary.ca

Specialty section:

This article was submitted to

Microbiotechnology, Ecotoxicology

and Bioremediation,

a section of the journal

Frontiers in Microbiology

Received: 12 February 2019

Accepted: 20 May 2019

Published: 18 June 2019

Citation:

Suri N, Gassara F, Stanislav P and

Voordouw G (2019) Microbially

Enhanced Oil Recovery by

Alkylbenzene-Oxidizing

Nitrate-Reducing Bacteria.

Front. Microbiol. 10:1243.

doi: 10.3389/fmicb.2019.01243
Microbially enhanced oil recovery (MEOR) of heavy oil and bitumen is challenging because light hydrocarbons, which can feed resident microbial communities are present in low concentrations, if at all. We have recently shown that increasing the toluene concentration of heavy oil by aqueous injection followed by injection of nitrate boosts the activity of toluene-oxidizing nitrate-reducing bacteria in heavy oil-containing sand pack columns, giving production of residual oil in place (ROIP). In the current work we found that ethylbenzene is as effective as toluene. Microbial community analyses indicated Thauera and Pseudomonas to be main components of nitrate-containing batch and continuous cultures, regardless whether ethylbenzene or toluene was used as the electron donor. Biomass from batch cultures grown with heavy oil amended with ethylbenzene or toluene and nitrate or biomass from continuous cultures grown on ethylbenzene or toluene and nitrate had similar MEOR activity. Increasing the concentration of injected biomass from continuous cultures increased the fraction of ROIP recovered both in the absence and in the presence of nitrate. Nitrate increased the fraction of ROIP recovered by about 2-fold by increasing the concentration of biomass in the columns. Emulsification of oil by surface-adhering biomass and blocking of aqueous flow channels by oil emulsion droplets are proposed as a possible mechanism of hydrocarbon- and nitrate-mediated MEOR. Pure isolates Thauera sp. NS1 and Pseudomonas sp. NS2, which used both ethylbenzene and toluene, were obtained but did not offer improved MEOR compared to the use of batch and continuous cultures.

\section{Keywords: MEOR, alkylbenzenes, nitrate, Thauera, biomass, oil emulsification}

\section{INTRODUCTION}

Alkylbenzenes, such as toluene, ethylbenzene and xylenes are monocyclic aromatic constituents of oil. Diverse alkylbenzene-oxidizing nitrate-reducing bacteria (ABO-NRB) of the phylum Proteobacteria have been enriched from hydrocarbon rich environments, including oil fields (Spormann and Widdel, 2000; Chakraborty and Coates, 2004; Lambo et al., 2008; Agrawal et al., 2012). This includes toluene-oxidizing NRB of the genera Thauera and Azoarcus (Rabus et al., 1999; Spormann and Widdel, 2000; Weelink et al., 2010). Enhanced growth of tolueneoxidizing NRB in heavy oil containing sand-packed columns increased recovery of residual oil in place (ROIP; Gassara et al., 2015). This was achieved through amendment or through sequential injection of aqueous toluene, to increase its concentration in oil, followed by injection 
of nitrate and NRB (Gassara et al., 2015). The formation of gaseous $\mathrm{N}_{2}$ and $\mathrm{CO}_{2}$, emulsifying biomass and/or biosurfactants were suggested as possible causes for this microbially enhanced oil recovery (MEOR).

Accumulation of biomass and associated exopolysaccharides can cause selective plugging of high permeability zones in bioreactors or reservoirs, which is one of the suggested mechanisms for MEOR (Sen, 2008; Youssef et al., 2009; Siegert et al., 2013). Increasing the toluene concentration in the oil phase and the nitrate concentration in the aqueous phase increased biomass growth and the proportions of Thauera and Pseudomonas species in the ABO-NRB consortia (Gassara et al., 2015; Suri et al., 2017). These taxa can produce exopolysaccharides that may also contribute to selective plugging (Allen et al., 2004; Schmid et al., 2015). In addition to toluene, Thauera and Pseudomonas species can also oxidize ethylbenzene under nitrate-reducing conditions (Chakraborty and Coates, 2004; Rabus, 2005; Weelink et al., 2010). Although toluene and ethylbenzene are chemically similar, the metabolic pathways for their oxidation are different (Champion et al., 1999), which may give changed metabolic outcomes (formation of biomass and biomolecules).

In the current paper the MEOR potential of using ethylbenzene was evaluated. Continuous cultures using ethylbenzene or toluene and nitrate were established and selected pure cultures of Thauera and Pseudomonas were isolated to identify the contribution of these taxa to hydrocarbon- and nitrate-mediated MEOR.

\section{MATERIALS AND METHODS}

\section{Batch and Continuous Cultures of ABO-NRB}

Produced water from producing well 18PW in the Medicine Hat Glauconitic C (MHGC) field (Voordouw et al., 2009; Shen et al., 2018) from which heavy oil with an API gravity of $16^{\circ}$ was produced was used as a source of microorganisms. For primary batch cultures $5 \mathrm{~mL}$ of $18 \mathrm{PW}$ was used to inoculate $44 \mathrm{~mL}$ of sterile anaerobic CSBK medium (Supplementary Table S1) either with or without $80 \mathrm{mM}$ nitrate in $120 \mathrm{~mL}$ serum bottles. MHGC oil $(1 \mathrm{~mL})$ with or without additional ethylbenzene or toluene was added to these bottles (Table 1). The bottles were sealed with butyl rubber stoppers, crimped with aluminum seals and had a $70 \mathrm{~mL}$ headspace of $90 \% \mathrm{~N}_{2}$ and $10 \% \mathrm{CO}_{2}\left(\mathrm{~N}_{2}-\mathrm{CO}_{2}\right)$. These were incubated upside down on a horizontal shaker ( $80 \mathrm{rpm}$ ) at $30^{\circ} \mathrm{C}$ for 35 days. Secondary batch cultures in the same growth media as used for primary cultures were inoculated with $5 \mathrm{~mL}$ of centrifuged and re-suspended primary culture (Table 1: B_EN) as the inoculum. These were incubated with shaking for 20 days.

Alkylbenzene-oxidizing nitrate-reducing bacteria continuous cultures were established by inoculating anaerobic CSBK medium with $10 \mathrm{mM}$ nitrate and $10 \mathrm{~mL}$ of $18 \mathrm{PW}$ in $160 \mathrm{~mL}$ chemostats. Continuous cultures were either with or without $2 \mathrm{~mL}$ of heptamethylnonane (HMN) as the inert hydrocarbon carrier. To the HMN layer $60.6 \mathrm{mM}$ ethylbenzene or $71.2 \mathrm{mM}$ toluene was added for reduction of $10 \mathrm{mM}$ nitrate in the $98 \mathrm{~mL}$ aqueous phase. When HMN was absent, $1.2 \mathrm{mM}$ ethylbenzene or $1.4 \mathrm{mM}$ toluene was dissolved directly in CSBK medium. Note that the solubilities of ethylbenzene and toluene in water at $20^{\circ} \mathrm{C}$ are 1.5 and $5.6 \mathrm{mM}$, respectively. The chemostats were sealed with butyl rubber stoppers, crimped with aluminum seals and had a $60 \mathrm{~mL}$ headspace of $\mathrm{N}_{2}-\mathrm{CO}_{2}$. Duplicate chemostats were incubated without flow on a horizontal stir plate $(200 \mathrm{rpm})$ at $22-25^{\circ} \mathrm{C}$ for 9 days. The chemostats were then connected to influent from a medium reservoir and to effluent containers (Supplementary Figure S1) at an initial flow rate of $10 \mathrm{~mL} /$ day, corresponding to a dilution rate (D) of $0.1 \mathrm{~d}^{-1}$. Note that all the continuous culture chemostats received an input of CSBK medium with $10 \mathrm{mM}$ nitrate and $1.2 \mathrm{mM}$ ethylbenzene or $1.4 \mathrm{mM}$ toluene. After 29 days of operation the flow rate was increased to $20 \mathrm{~mL} /$ day $\left(0.2 \mathrm{~d}^{-1}\right)$. Samples $(200 \mu \mathrm{L})$ were collected periodically from the sampling port (Supplementary Figure S1) for nitrate and nitrite measurements using high performance liquid chromatography as explained earlier (Agrawal et al., 2012; Suri et al., 2017).

\section{Microbial Community Analysis of Batch and Continuous ABO-NRB Cultures}

Primary and secondary batch cultures were transferred into $50 \mathrm{~mL}$ Falcon tubes at the end of incubation. While the continuous culture effluents $(1 \mathrm{~mL})$ were collected in $1.5 \mathrm{~mL}$ microcentrifuge tubes at the sampling port (Supplementary Figure S1) at different times of operation. Samples were centrifuged at 10,000 rpm for $30 \mathrm{~min}$. Following centrifugation, the supernatants were carefully discarded and the cell pellets were used for extracting DNA. The extracted DNA was subjected to PCR amplification of 16S rRNA genes using primers based on $926 \mathrm{Fw}$ and $1392 \mathrm{R}$ in a two-step PCR procedure as described elsewhere (An et al., 2013; Suri et al., 2017; Menon and Voordouw, 2018). The resulting purified 420 bp PCR product was sequenced using the 300PE (paired-end) MiSeq protocol on an Illumina Miseq system in the Energy Bioengineering and Geomicrobiology Group, University of Calgary. The 300PE reads were merged using PEAR 0.9.6 with a minimum $50 \mathrm{bp}$ overlap and were further processed with a 420 bp cutoff of amplicon size using MetaAmp, a 16S rRNA data analysis pipeline, which was also used for bioinformatic analysis ${ }^{1}$ (Dong et al., 2017). Quality controlled (QC) sequences were clustered into operational taxonomic units (OTU's) using average neighbor clustering at a distance of $3 \%$. OTU's were assigned to taxa by comparing with the latest version of the nonredundant 16S rRNA small subunit SILVA database. Samples were clustered into a dendrogram using the unweighted pair group method algorithm (UPGMA) and the distance between communities was calculated as the Bray-Curtis coefficient in Mothur software (Dong et al., 2017). The dendrogram was visualized using the Mega 7.0.26 (Kumar et al., 2016). The entire sets of 16S rRNA gene amplicon raw reads

${ }^{1}$ http://ebg.ucalgary.ca/metaamp 
have been submitted to the NCBI sequence read archive (SRA) under Bioproject accession numbers SAMN10280305 to SAMN10280325.

\section{Isolation and Identification of ABO-NRB}

Serially diluted samples from continuous cultures were plated on CSBK medium with $10 \mathrm{mM}$ acetate and $10 \mathrm{mM}$ nitrate, solidified with $15 \mathrm{~g} / \mathrm{L}$ of agar. The plates were incubated upside down at room temperature $\left(22-25^{\circ} \mathrm{C}\right)$ in an anaerobic hood with an atmosphere of $\mathrm{N}_{2}-\mathrm{CO}_{2}$. Individual colonies were picked and grown in $1 \mathrm{~mL}$ of anaerobic CSBK medium with $10 \mathrm{mM}$ acetate and $10 \mathrm{mM}$ nitrate in $2 \mathrm{~mL}$ screw capped glass vials. After 3 days of incubation, $100 \mu \mathrm{L}$ of cultures that showed high turbidity were transferred to $1 \mathrm{~mL}$ of CSBK medium amended with $10 \mathrm{mM}$ nitrate and with $5 \mathrm{mM}$ benzoate, $1.2 \mathrm{mM}$ ethylbenzene or $1.4 \mathrm{mM}$ toluene. Transferred cultures that grew with all three of the electron donors were streaked on CSBK medium with $10 \mathrm{mM}$ nitrate, solidified with $15 \mathrm{~g} / \mathrm{L}$ of agar. The plates were incubated at room temperature $\left(22-25^{\circ} \mathrm{C}\right)$ in anaerobic jars containing a crystallizing dish with $200 \mu \mathrm{L}$ of ethylbenzene or toluene in $2 \mathrm{~mL}$ of HMN. The jars were kept in the anaerobic hood throughout the incubation. Colonies picked from these plates were suspended in $10 \mu \mathrm{L}$ Tris-EDTA buffer (Sigma-Aldrich) in $200 \mu \mathrm{L}$ PCR tubes (Bio-Rad) and incubated for $5 \mathrm{~min}$ at $95^{\circ} \mathrm{C}$. $16 \mathrm{~S}$ rRNA genes were then amplified with primers $27 \mathrm{~F}$ and 1525R (Frank et al., 2008) in a $50 \mu \mathrm{L}$ volume containing premade PCR reagents (Thermo Fisher Scientific). The PCR was for 25 cycles of $30 \mathrm{~s}$ at $95^{\circ} \mathrm{C}$, $2 \mathrm{~min}$ at $72^{\circ} \mathrm{C}$, followed by a final incubation at $72^{\circ} \mathrm{C}$ for $7 \mathrm{~min}$. The quality of the PCR products was evaluated by electrophoresis on a $1.5 \%(\mathrm{w} / \mathrm{v})$ agarose gel. PCR products were purified using the QIAquick PCR purification kit (Qiagen, Germany), quantified and subjected to Sanger sequencing at the Core DNA Services Laboratory of the University of Calgary $^{2}$. The resulting 1500 bp sequences were compared with sequences in the GenBank database of the National Center for Biotechnology Information (NCBI) using the nucleotidenucleotide blast (blastn) network service ${ }^{3}$. The 16S rRNA gene sequences of Thauera sp. NS1 and Pseudomonas sp. NS2 isolated

\footnotetext{
${ }^{2}$ http://www.sequencing.ucalgary.ca

${ }^{3}$ https://blast.ncbi.nlm.nih.gov/Blast.cgi
}

in this study were submitted to GenBank with accession numbers MK085068 and MK085069, respectively.

\section{Phylogenetic Analysis of 16S rRNA Gene Sequences of Thauera Species}

The 16S rRNA gene sequences of different Thauera species obtained from the NCBI nucleotide database ${ }^{4}$ are listed in Supplementary Table S2. Thauera affiliated 16 S rRNA sequences from batch and continuous cultures were obtained with MetaAmp (see text footnote 1; Dong et al., 2017). These sequences were aligned using ClustalX version 2.0 in the multiple alignment mode (Larkin et al., 2007). The aligned sequences were trimmed to 420 bp by removing the upstream and downstream flanking regions including the primer sequences using BioEdit Sequence Alignment Editor version 7.2.5 (Hall, 1999). Phylogenetic analysis of the trimmed aligned sequences was carried out using MEGA version 7.0.26 (Kumar et al., 2016). The 16S rRNA sequence of Acetobacter peroxydans (GenBank Accession no. AB032352) was used as an outgroup in the phylogenetic analysis. Distances were computed using distance options according to Kimura's two-parameter model (Kimura, 1980) and clustering was performed with the neighbor-joining method (Saitou and Nei, 1987). Statistical support for branches of the phylogenetic tree was obtained through bootstrap analysis based on 1500 resamplings (Felsenstein, 1985).

\section{Growth of ABO-NRB Isolates on Different Electron Donors}

Isolated ABO-NRB were grown in $120 \mathrm{~mL}$ serum bottles with sterile anaerobic CSBK medium with $10 \mathrm{mM}$ nitrate. Higher nitrate concentrations were used in some experiments. The bottles had $1 \mathrm{~mL}$ of $\mathrm{HMN}(2 \% \mathrm{v} / \mathrm{v}$ of total volume of $50 \mathrm{~mL}$ ). Either $6.5 \mathrm{mM}$ of aqueous acetate, $1.7 \mathrm{mM}$ of aqueous benzoate, $60.6 \mathrm{mM}$ of ethylbenzene in HMN or $71.2 \mathrm{mM}$ of toluene in HMN was added as electron donor. Samples $(200 \mu \mathrm{L})$ were taken periodically into $1.5 \mathrm{~mL}$ microfuge tubes using $\mathrm{N}_{2}-\mathrm{CO}_{2}$ flushed syringes to measure nitrate and nitrite concentrations by high performance liquid chromatography.

${ }^{4}$ https://www.ncbi.nlm.nih.gov/nucleotide/

TABLE 1 | The percentage (\%) reduction of nitrate by ABO-NRB enriched in batch cultures containing 2\% (v/v) MHGC oil with or without additional electron donor.

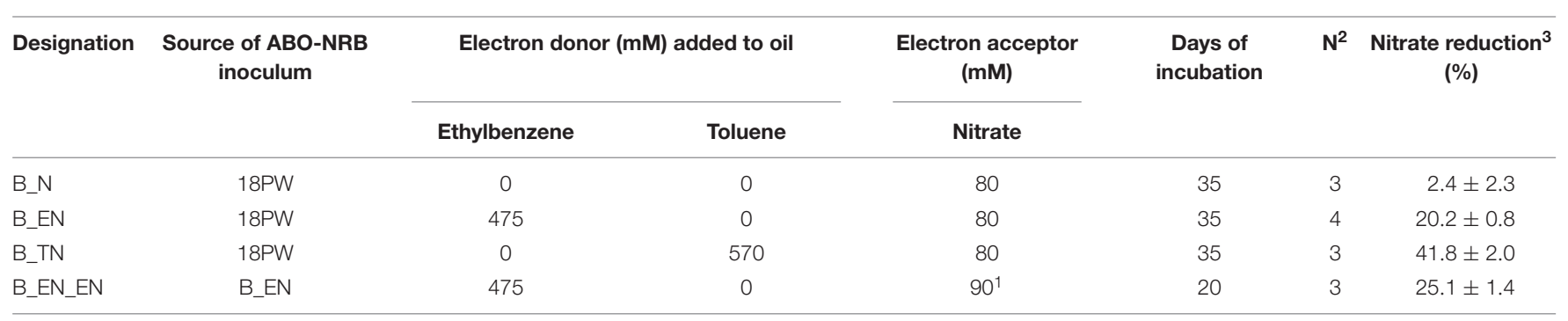

These were either inoculated with produced water 18PW from the MHGC field or ABO-NRB primary enrichment grown on $475 \mathrm{mM}$ ethylbenzene in $1 \mathrm{~mL}$ of oil and $80 \mathrm{mM}$ nitrate in $49 \mathrm{~mL}$ of aqueous phase (B_EN). Each value represents an average $\pm S D$ of three or four replicates. ${ }^{1} 10 \mathrm{mM}$ on day 0 and $80 \mathrm{mM}$ on day $6 .{ }^{2} \mathrm{Number}$ of replicates. ${ }^{3}$ Nitrate reduction (\%) $=$ (nitrite concentration/initial nitrate concentration) $* 40 \%+($ (initial nitrate concentration - residual nitrate concentration - nitrite concentration)/initial nitrate concentration)* $100 \%$. 


\section{Oil Production From Up-Flow Model High-Pressure Columns}

Vertically oriented stainless steel sand-pack columns were prepared and operated at high pressure (27.2 atm) and at room temperature $\left(22-25^{\circ} \mathrm{C}\right)$. Their pore volumes (PVs) were calculated by weighing them dry and following saturation with CSBK under upflow conditions. The columns were then injected with 1 PV of MHGC oil, which was unamended or amended with $9.5 \mathrm{mM}$ ethylbenzene or $11.2 \mathrm{mM}$ toluene. The injected heavy oil replaced approximately $0.95 \mathrm{PV}$ of CSBK medium from the columns. Heavy oil was then produced from the columns by injection of CSBK at a rate of $1 \mathrm{PV} /$ day for 2 weeks. Produced oil was measured by dichloromethane extraction of the oil-water effluent mixture followed by determination of the absorbance at $600 \mathrm{~nm}\left(\mathrm{~A}_{600}\right)$ of the oil-dichloromethane layer as described previously (Kryachko and Voordouw, 2014; Gassara et al., 2015). This allowed calculation of the volume $(\mathrm{mL})$ of residual oil in place (ROIP). Approximately 0.5 PV of ROIP remained in the columns. The columns were then injected with ABO-NRB in 0.5 PV of CSBK with or without $80 \mathrm{mM}$ nitrate. Following injection, columns were closed at both ends and incubated under pressure without flow for 2.5 weeks (Gassara et al., 2015). Upflow injection of CSBK medium was then resumed at a rate of $1 \mathrm{PV} /$ day. Apart from measurement of oil produced from the columns, the effluents collected were also analyzed for the concentrations of nitrate and nitrite in the aqueous phase using HPLC and of ethylbenzene or toluene in the oil phase using GC-MS as described elsewhere (Agrawal et al., 2012; Gassara et al., 2015; Suri et al., 2017).

\section{RESULTS}

\section{Nitrate Reduction by ABO-NRB in Batch Cultures}

The concentrations of ethylbenzene and toluene in MHGC oil as determined by GC-MS analysis were $3.0 \pm 0.9$ and $2.6 \pm 0.6 \mathrm{mM}$, respectively. Incubation of CSBK medium with $80 \mathrm{mM}$ nitrate and $1 \mathrm{~mL}$ of MHGC oil inoculated with $18 \mathrm{PW}$ gave reduction of $2.4 \pm 2.3 \%$ of nitrate after 35 days (Table 1: B_N). Adding $475 \mathrm{mM}$ ethylbenzene or $570 \mathrm{mM}$ toluene to the $1 \mathrm{~mL}$ oil phase, sufficient for reduction of $80 \mathrm{mM}$ nitrate in the $49 \mathrm{~mL}$ aqueous phase, increased the reduction of nitrate to $20.2 \pm 0.8$ and $41.8 \pm 2.0 \%$, respectively (Table 1: B_EN and B_TN). Secondary batch culture incubation of primary enrichment B_EN in medium with nitrate and MHGC oil with $475 \mathrm{mM}$ ethylbenzene gave $25.1 \pm 1.4 \%$ nitrate reduction (Table 1: B_EN_EN). Hence, significantly increased nitrate reduction was obtained by adding ethylbenzene or toluene to the oil phase.

\section{Nitrate Reduction by ABO-NRB in Continuous Cultures}

Batch cultures of ABO-NRB reduced $80 \mathrm{mM}$ nitrate only partially in the presence of heavy oil with added ethylbenzene or toluene (Table 1). To try to achieve more complete nitrate reduction and thus potentially higher biomass concentrations continuous cultures of ABO-NRB were started. ABO-NRB were initially enriched by inoculation of the CSBK medium in the chemostats with 18PW and incubation in the absence of flow (Figure 1: day 0 to 9$)$. Nitrate $(10 \mathrm{mM})$ was completely reduced to nitrite after 3 and 2 days of incubation in cultures with $60.6 \mathrm{mM}$ ethylbenzene and $71.2 \mathrm{mM}$ toluene in the HMN phase, respectively (Figures 1A,B). The reduction of nitrate to nitrite in cultures with $1.2 \mathrm{mM}$ ethylbenzene and $1.4 \mathrm{mM}$ toluene in the aqueous phase without HMN was slower with complete reduction of nitrate to nitrite observed after 7 and 3 days, respectively (Figures 1C,D). The formation of nitrite in all these cultures was transient with most being reduced to $\mathrm{N}_{2}$ at day 9. Flow was then started by injection of CSBK medium with $10 \mathrm{mM}$ nitrate and $1.2 \mathrm{mM}$ ethylbenzene or $1.4 \mathrm{mM}$ toluene at a rate of $10 \mathrm{~mL} /$ day (dilution rate, $D=0.1 \mathrm{~d}^{-1}$ ). The effluent nitrate concentrations increased to $2-3 \mathrm{mM}$ in the chemostats with an HMN phase (Figures 1A,B) and without an HMN phase (Figures 1C,D). However, the effluent concentrations of nitrate and nitrite decreased to zero at day 20 in all continuous cultures, irrespective of the presence or absence of an HMN phase (Figure 1). Increasing the rate of medium influx to $20 \mathrm{~mL} /$ day $\left(D=0.2 \mathrm{~d}^{-1}\right)$ gave incomplete reduction of nitrate and nitrite with effluent concentrations of up to 5 to $7 \mathrm{mM}$ from day 35 to 65 (Figure 1) after which the effluent nitrate and nitrite concentrations remained at zero. Overall, the nitrate and nitrite concentrations in the chemostat effluents increased transiently with each increase in dilution rate. These increases were higher in the transition from $D=0.1 \mathrm{~d}^{-1}$ to $D=0.2 \mathrm{~d}^{-1}$ than in the transition from $D=0 \mathrm{~d}^{-1}$ to $D=0.1 \mathrm{~d}^{-1}$ (Figure 1 ). There was little difference in the kinetic profiles of nitrate reduction and nitrite production and reduction between chemostats fed with ethylbenzene or toluene and between chemostats with or without an HMN phase. The biomass concentrations in the ethylbenzenefed and the toluene-fed continuous cultures, as measured by the $\mathrm{OD}_{600}$, at 65 days were similar at $\mathrm{OD}_{600}=3.12$ and $\mathrm{OD}_{600}=3.35$, respectively.

\section{Microbial Community Compositions of Produced Water and of Batch and Continuous ABO-NRB Cultures}

The microbial community compositions of produced water 18PW, batch cultures and continuous cultures are compared in Figure 2 and Supplementary Table S3. A dendrogram of these compositions indicated that $18 \mathrm{PW}$ was in a separate clade I. Clade II contained most of the batch culture community compositions, whereas clade III contained the microbial communities of batch culture B_TN and of all of the continuous cultures. Within clade III, the microbial communities of continuous cultures at day $23\left(D=0.1 \mathrm{~d}^{-1}\right)$ and at day $63\left(D=0.2 \mathrm{~d}^{-1}\right)$ formed two subclades. Further subclustering separated microbial communities of ethylbenzenefed from those of toluene-fed cultures. The presence or absence of an HMN phase had the smallest impact on microbial community compositions (Figure 2). The microbial communities within a particular clade had a similar composition 

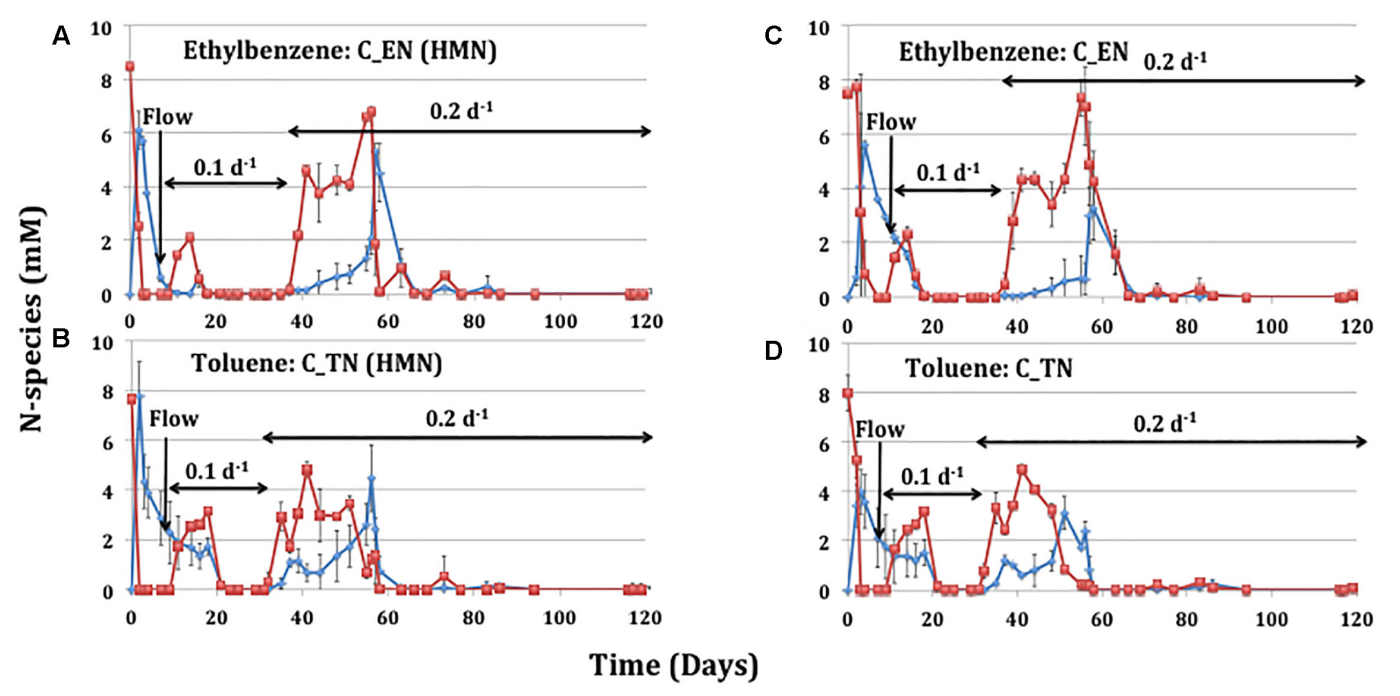

FIGURE 1 | Concentrations of nitrate $(\square)$ and nitrite $(\bullet)$ in effluents of ABO-NRB continuous cultures as a function of time. The continuous cultures were maintained at dilution rates of 0.1 or $0.2 \mathrm{~d}^{-1}$. Prior to starting flow the cultures were grown in $98 \mathrm{~mL}$ of aqueous medium with $10 \mathrm{mM}$ nitrate and (A) $60.6 \mathrm{mM}$ ethylbenzene in $2 \mathrm{~mL}$ of HMN, (B) $71.2 \mathrm{mM}$ toluene in $2 \mathrm{~mL}$ of HMN or in $100 \mathrm{~mL}$ of aqueous medium with $10 \mathrm{mM}$ nitrate and (C) $1.2 \mathrm{mM}$ of aqueous ethylbenzene or (D) $1.4 \mathrm{mM}$ of aqueous toluene. During flow the continuous cultures received medium with $10 \mathrm{mM}$ nitrate and $1.2 \mathrm{mM}$ of aqueous ethylbenzene (A,C) or $1.4 \mathrm{mM}$ of aqueous toluene (B,D)

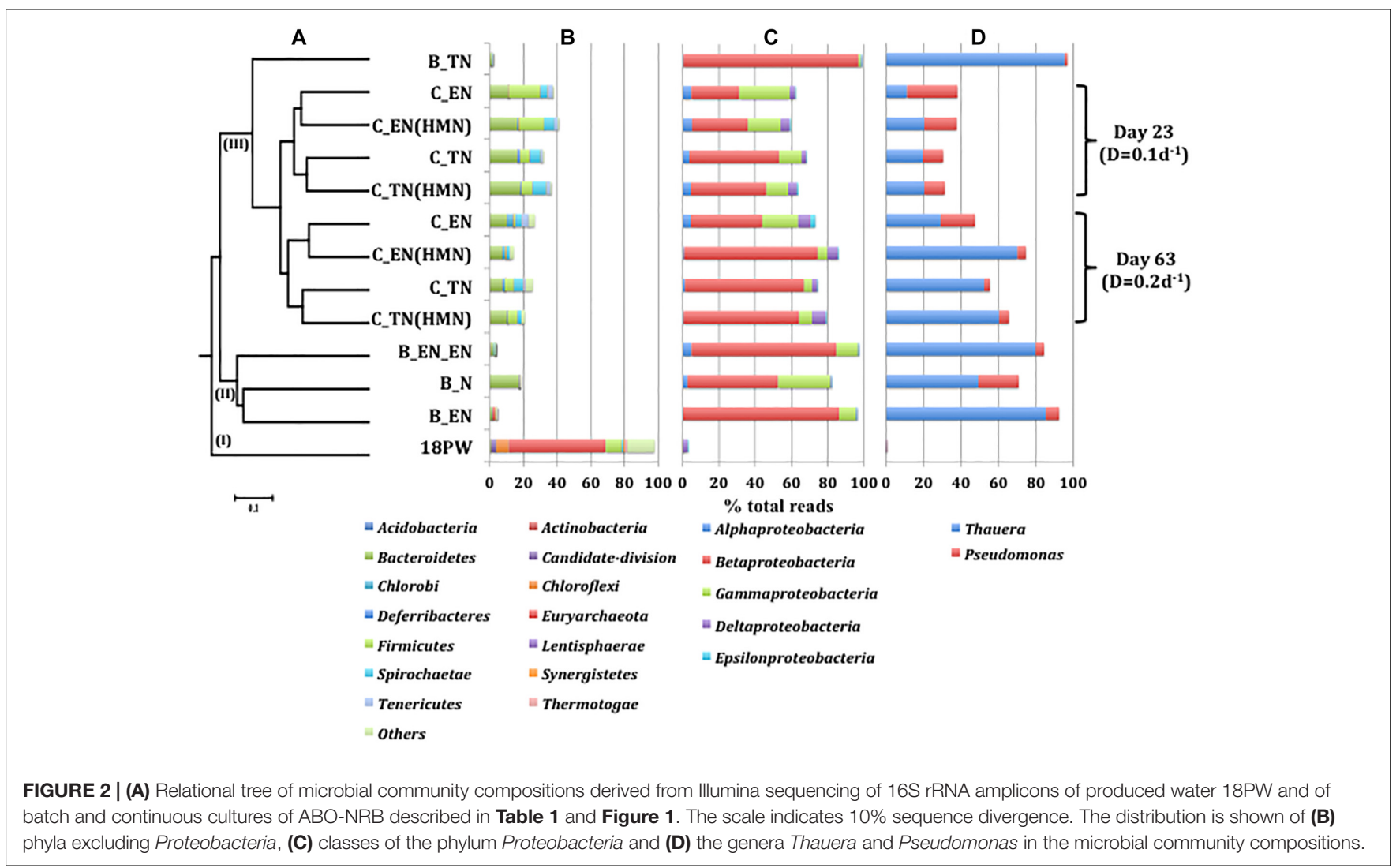

at the phylum level (Figure 2B), had a similar distribution of classes within the phylum Proteobacteria (Figure 2C), and had similar proportions of the genera Thauera and Pseudomonas (Figure 2D).
The microbial community of the $18 \mathrm{PW}$ produced water sample, which was produced together with MHGC oil, was more diverse than the communities in batch cultures with MHGC oil with additional ethylbenzene or toluene and nitrate, as indicated 
by Shannon indices of 2.3 and of $0.5-1.6$, respectively. The microbial community compositions of continuous cultures at day $23\left(D=0.1 \mathrm{~d}^{-1}\right)$ had higher Shannon indices of 2.82.9 than those at day $63\left(D=0.2 \mathrm{~d}^{-1}\right)$, which were $1.5-2.6$ (Supplementary Table S3). The presence of HMN decreased the diversity at $D=0.2 \mathrm{~d}^{-1}$, but not at $D=0.1 \mathrm{~d}^{-1}$. The presence of HMN decreases the aqueous alkylbenzene concentration available to the microbial community, whereas a decrease in dilution rate decreases the specific growth rate constant of the microbial community.

Produced water 18PW had a high proportion of the phylum Euryarchaeota (Figure 2B), genus Methanoculleus (Supplementary Table S3: 53\%). This taxon was a minor community component in batch cultures with nitrate and heavy oil with or without additional ethylbenzene or toluene and was absent from continuous cultures with nitrate and ethylbenzene or toluene. These were, instead, dominated by the phylum Proteobacteria (Figure 2C) with the genus Thauera being most prominent throughout (Figure 2D and Supplementary Table S3). The genus Pseudomonas was on average the second most prominent taxon. The fraction of Thauera was highest in batch culture B_TN (95.3\%). This batch culture also had the highest percentage of nitrate reduction (Table 1). Batch cultures B_EN and B_EN_EN also had high fractions of Thauera of 85.3 and $79.8 \%$, respectively.

The average fraction of Thauera in continuous cultures was $17.8 \%$ at day $23\left(D=0.1 \mathrm{~d}^{-1}\right)$ and increased to $52.9 \%$ at day $63\left(D=0.2 \mathrm{~d}^{-1}\right)$. This increase in the fraction of Thauera was seen irrespective whether ethylbenzene or toluene was the electron donor and was stronger in continuous cultures with an HMN phase as compared to the cultures without an HMN phase. The average fraction of Pseudomonas in continuous cultures was $16.6 \%$ at day $23\left(D=0.1 \mathrm{~d}^{-1}\right)$, which decreased to $7.8 \%$ at day $63\left(D=0.2 \mathrm{~d}^{-1}\right)$. These results indicated Thauera to be the main player in catalyzing alkylbenzene oxidation coupled to nitrate reduction. The increased diversity of continuous cultures as compared to batch cultures was associated with higher fractions of phyla other than Proteobacteria (Figure 2B) and of genera Acetoanaerobium, Desulfuromonas, and Sphaerochaeta (Supplementary Table S3).

\section{Identification of Isolated ABO-NRB}

Colonies with different sizes and morphologies appeared on agar surfaces plated with continuous ABO-NRB cultures. Two distinct bacterial isolates were obtained by subsequent plating of individual colonies picked from these plates. Both were able to grow in the presence of acetate, benzoate, ethylbenzene or toluene as electron donors and nitrate as the electron acceptor. The full length 16S rRNA sequence of isolate NS1 had 99.0\% 16S rRNA sequence identity to Thauera aromatica strain S100 (Mechichi et al., 2002), whereas that of isolate NS2 had 99.0\% 16S rRNA sequence identity to Pseudomonas stutzeri strain NBRC 12695 (Nakagawa et al., 2011). The Pseudomonas sp. NS2 colonies were bigger and were disc shaped with ridges radiating from the center, whereas the Thauera sp. NS1 colonies were smaller with a smooth surface appearance (Supplementary Figure S2).

\section{Comparison of Isolated Thauera Species With Those in ABO-NRB Cultures}

A comparative phylogenetic analysis of the $420 \mathrm{bp}$ region of the 16S rRNA gene sequences of Thauera species in microbial communities of ABO-NRB batch and continuous cultures and of Thauera sp. NS1 with sequences retrieved from the NCBI database (Supplementary Table S2) showed their similarity to Thauera aromatica (Figure 3). The 420 bp $16 \mathrm{~S}$ rRNA sequences of Thauera sp. B_TN, B_EN, C_TN(HMN) and C_EN(HMN) from batch or continuous cultures and of the isolated Thauera sp. NS1 were found to be very similar to those of T. aromatica strains T1, 3CB2, 3CB3, S100, and K172 (Figure 3 and Supplementary Table S4: $98.3-100 \%$ identity). These sequences were less similar to those of other Thauera species (Figure 3 and Supplementary Table S4: 97.6-99.0\% identity).

\section{Nitrate Reduction by ABO-NRB Isolates in Batch Cultures}

Nitrate $(10 \mathrm{mM})$ was completely reduced to $\mathrm{N}_{2}$ with transient formation of nitrite in batch cultures with Thauera sp. NS1 or Pseudomonas sp. NS2 or both (Figure 4 and Supplementary Figure S3). Based on the equations presented in Supplementary Table S5 reduction of $10 \mathrm{mM}$ nitrate is coupled to the oxidation

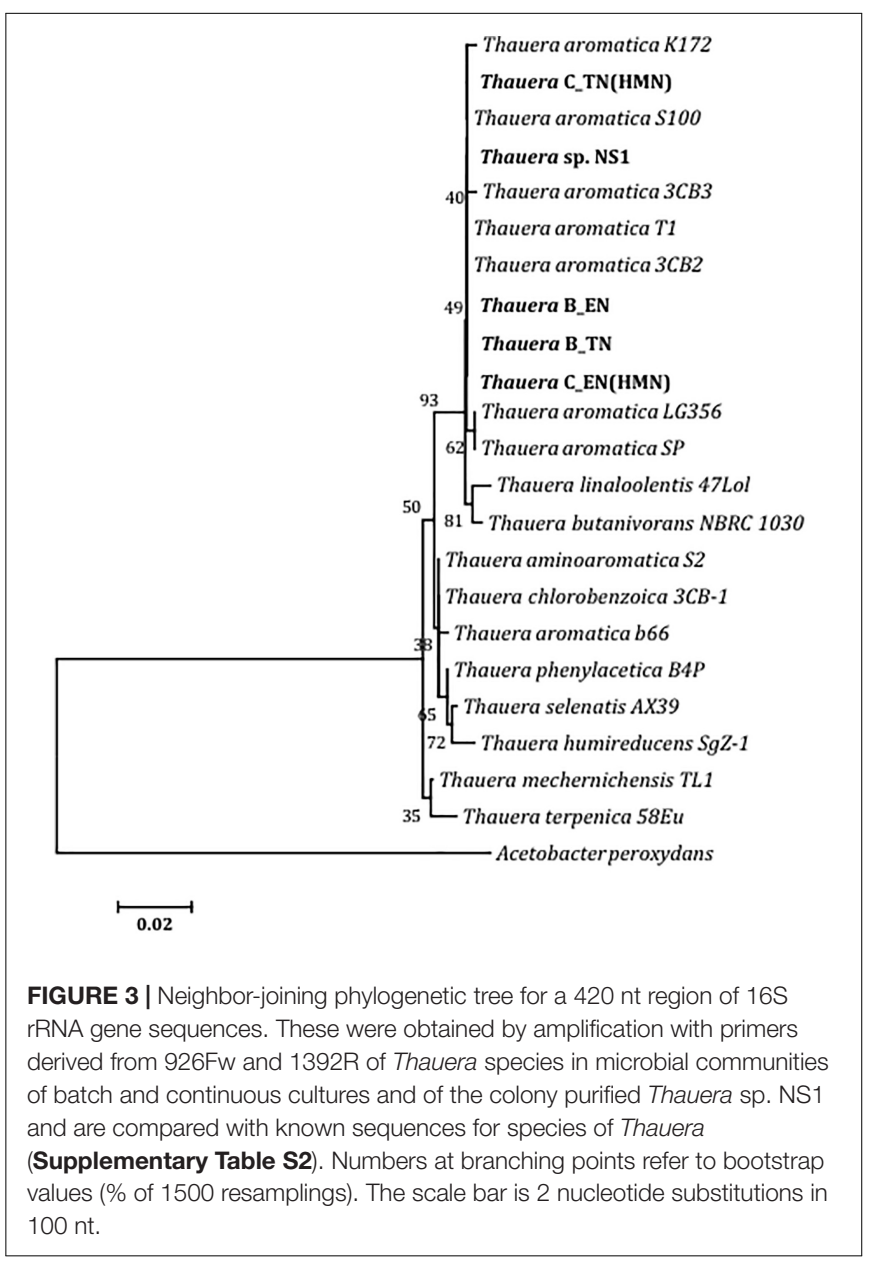




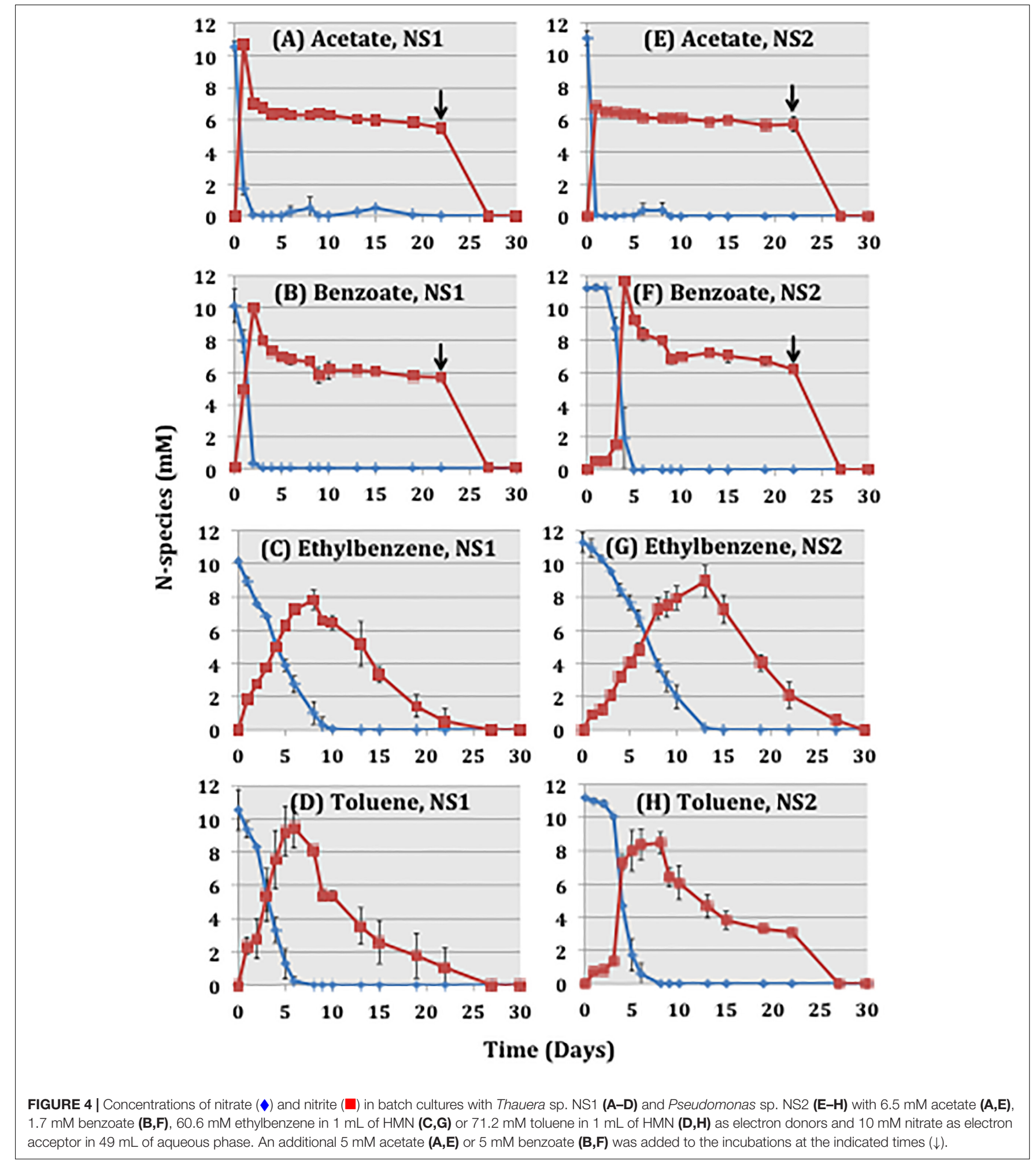

of $6.25 \mathrm{mM}$ acetate, $1.72 \mathrm{mM}$ benzoate, $1.39 \mathrm{mM}$ toluene, or $1.19 \mathrm{mM}$ ethylbenzene. Adding these stoichiometric concentrations gave complete reduction of nitrate to nitrite and of nitrite to $\mathrm{N}_{2}$ with ethylbenzene and toluene (Figures 4C,D,G,H) but not with acetate and benzoate, where approximately $6 \mathrm{mM}$ nitrite remained (Figures $4 \mathrm{~A}, \mathbf{B}, \mathbf{E}, \mathbf{F}$ ). This indicates formation of larger amounts of other products, e.g., biomass or exopolysaccharides (Chen et al., 2017). Addition of another $5 \mathrm{mM}$ acetate or benzoate completed the reduction of nitrate. The kinetics of nitrate reduction was similar for 
the two isolates. NS2 oxidized benzoate, ethylbenzene and toluene somewhat more slowly than NS1. Incubations with equal proportions of NS1 and NS2 gave nitrate reduction rates similar to those of Thauera sp. NS1 (Supplementary Figure S3).

Batch cultures of Thauera sp. NS1 or Pseudomonas sp. NS2 with excess ethylbenzene or toluene as electron donor and 20, 40 or $80 \mathrm{mM}$ nitrate as electron acceptor gave nearly complete reduction of nitrate to $\mathrm{N}_{2}(98.0 \pm 1.8 \%)$ in cultures with $20 \mathrm{mM}$ nitrate. Batch cultures with 40 or $80 \mathrm{mM}$ nitrate reduced on average $40.3 \pm 11.4 \%$ and $29.0 \pm 12.9 \%$ of nitrate, respectively, after 30 days of incubation (Table 2). The percent nitrate reduction observed with ethylbenzene was higher than with toluene in these incubations. Incubations with equal proportions of the two isolates did not significantly change the percentage of nitrate reduction (Table 2). Comparing the results obtained for batch cultures of NS1 and/or NS2 with those for enrichment cultures of 18PW indicated that none of these were able to reduce $80 \mathrm{mM}$ nitrate with excess ethylbenzene or toluene in the HMN or in the oil phase, respectively (Tables 1,2 ).

\section{Oil Production From Heavy-Oil Containing Columns at High Pressure}

Heavy oil-containing columns at high pressure (27.2 atm) were used to determine the effect of ABO-NRB on oil production, because these offer a better simulation of the reservoir environment than low pressure ( $1 \mathrm{~atm}$ ) columns (Gassara et al., 2015). Less gas phase $\mathrm{N}_{2}$ and $\mathrm{CO}_{2}$, which displaces the residual oil in place (ROIP), is produced at higher pressure. Flooding of the columns with CSBK medium allowed the pore volume (PV) to be measured (Supplementary Table S6). Columns were then flooded with 1 PV of MHGC oil, usually with an added concentration of $9.5 \mathrm{mM}$ ethylbenzene or $11.2 \mathrm{mM}$ toluene then again with $15 \mathrm{PV}$ of CSBK over a 15-day period. By monitoring the accumulative oil production, the ROIP could be estimated (Supplementary Table S6). The fraction of the pore volume occupied by oil (ROIP/PV) at the start of the MEOR experiment varied from 0.34 to 0.62 (Table 3 ) with the average being $0.49 \pm 0.08(N=23)$. Injection of $0.5 \mathrm{PV}$ of an ABO-NRB consortium with or without $80 \mathrm{mM}$ nitrate was then done, as indicated in Table 3.

The negative controls (columns 1 to 4) lacked injected $\mathrm{ABO}-\mathrm{NRB}$ and also either alkylbenzene or nitrate. These gave production of $2.5 \pm 0.1 \%$ and $5.4 \pm 4.5 \%$ of ROIP, respectively (Table 3). An average value of $4.1 \pm 2.6 \%(N=4)$ was therefore used as the value for the negative control.

Columns 5 and 6, containing heavy oil spiked with $9.5 \mathrm{mM}$ ethylbenzene and injected with ABO-NRB and $80 \mathrm{mM}$ nitrate, gave $16.0 \pm 1.9 \%$ of ROIP (Table 3 ). This value was similar as obtained for heavy oil spiked with $11.2 \mathrm{mM}$ toluene in previous work under the same conditions (Gassara et al., 2015), which was $17.9 \pm 1.7 \%(N=3)$ of ROIP. Nitrate was reduced in both of these sets of columns (Supplementary Table S6: $89.3 \pm 1.0$ and Gassara et al. (2015): $80.5 \pm 7.8 \%$, respectively). A larger increase in differential pressure $(\Delta \mathrm{P})$ was observed in columns with nitrate than in columns without nitrate, when water injection was restarted after incubation with ABO-NRB
(Supplementary Figure S4). This was also observed for columns with oil with added toluene (Gassara et al., 2015). In terms of the Darcy equation the increased $\Delta \mathrm{P}$ was interpreted as being required to compensate for a decrease in the effective area A for water flow through the columns following incubation (Gassara et al., 2015). The decrease in A may reflect blocking of aqueous flow channels through produced biomass and/or emulsified oil droplets.

Hence, increasing the concentration of ethylbenzene or toluene in heavy MHGC oil allowed reduction of more nitrate and gave a net production of 12.0 to $13.9 \%$ of ROIP. Ethylbenzene was as effective as toluene.

\section{Oil Production as a Function of ABO-NRB Biomass Concentration}

Continuous cultures growing on ethylbenzene or toluene and nitrate were used to determine the effect of injected biomass concentration on the production of oil. The biomass concentration, determined as the $\mathrm{OD}_{600}$, was 3.12 and 3.35 for continuous cultures at 65 days grown on ethylbenzene or toluene, respectively. $\mathrm{OD}_{600}$ cannot be used as a proxy for the biomass concentration in batch cultures grown in the presence of oil, which were injected in columns 5 and 6 (Table 3). A volume of $10 \mathrm{~mL}$ of the continuous cultures was centrifuged and re-suspended in $10 \mathrm{~mL}$ of CSBK and further diluted with $\mathrm{CSBK}$ to $\mathrm{OD}_{600}$ values ranging from 0.090 to 1.769 (Table 3). These diluted ABO-NRB cultures contained either 0 or $80 \mathrm{mM}$ nitrate and were then injected into columns 7 to 14 , containing oil with ethylbenzene or toluene. On average 57 to $96 \%$ of the injected nitrate was reduced during the subsequent 2-week incubation. Upon completion of incubation and resumption of CSBK injection these columns produced 5.5 to $21.9 \%$ of ROIP (Table 3).

Oil produced (\% ROIP) increased with the $\mathrm{OD}_{600}$ of injected biomass both in the absence and in the presence of nitrate, as indicated by equations 1 and 2, respectively, which were obtained by linear regression of the data in Figure 5.

$$
\% \text { ROIP }=4.8 \mathrm{OD}_{600}+6.1\left(r^{2}=0.947 ; N=4\right) \quad \text { Eq. } 1
$$

$$
\% \text { ROIP }=11.2 \mathrm{OD}_{600}+8.3\left(r^{2}=0.995 ; N=4\right) \quad \text { Eq. } 2
$$

Hence, at a given biomass concentration the presence of nitrate increased oil production (\% ROIP) by about 2-fold (Figure 5). A given production of additional oil (\% ROIP) required an injected biomass concentration that was 3.3-fold lower in the presence than in the absence of nitrate. This likely reflected the growth of $\mathrm{ABO}-\mathrm{NRB}$ in the presence of nitrate. Nitrate reduction was coupled to the oxidation of ethylbenzene or toluene in the oil phases of the columns. The average residual concentrations of ethylbenzene and toluene were $0.2 \pm 0.3 \mathrm{mM}$ $(N=2)$ and $0.9 \pm 0.8 \mathrm{mM}(N=2)$, respectively, in oil produced from columns with nitrate, whereas in columns without nitrate 6 
TABLE 2 | The percentage (\%) reduction of nitrate by Thauera sp. NS1 and Pseudomonas sp. NS2 in batch cultures containing $2 \%$ (v/v) HMN phase with dissolved electron donors.

\begin{tabular}{|c|c|c|c|c|}
\hline \multirow{2}{*}{$\begin{array}{l}\text { ABO-NRB isolate } \\
\text { inoculum }\end{array}$} & \multicolumn{2}{|c|}{ Electron donor (mM) } & \multirow{2}{*}{$\begin{array}{l}\text { Electron acceptor } \\
\qquad \begin{array}{c}(\mathrm{mM}) \\
\text { Nitrate }\end{array}\end{array}$} & \multirow{2}{*}{$\begin{array}{c}\text { Nitrate reduction }{ }^{1} \\
(\%)\end{array}$} \\
\hline & Ethylbenzene & Toluene & & \\
\hline NS1 & 475 & 0 & 20 & $95.3 \pm 1.1$ \\
\hline NS1 & 0 & 570 & 20 & $98.4 \pm 2.0$ \\
\hline NS2 & 475 & 0 & 20 & $98.3 \pm 1.8$ \\
\hline NS2 & 0 & 570 & 20 & $97.1 \pm 1.6$ \\
\hline $\mathrm{NS} 1+\mathrm{NS} 2$ & 475 & 0 & 20 & $99.4 \pm 0.1$ \\
\hline NS1+NS2 & 0 & 570 & 20 & $99.4 \pm 0.2$ \\
\hline Average \pm SD & & & & $98.0 \pm 1.8$ \\
\hline NS1 & 475 & 0 & 40 & $33.9 \pm 6.9$ \\
\hline NS1 & 0 & 570 & 40 & $31.8 \pm 0.6$ \\
\hline NS2 & 475 & 0 & 40 & $56.3 \pm 2.7$ \\
\hline NS2 & 0 & 570 & 40 & $33.9 \pm 2.8$ \\
\hline $\mathrm{NS} 1+\mathrm{NS} 2$ & 475 & 0 & 40 & $54.5 \pm 0.5$ \\
\hline $\mathrm{NS} 1+\mathrm{NS} 2$ & 0 & 570 & 40 & $31.7 \pm 1.8$ \\
\hline Average \pm SD & & & & $40.3 \pm 11.4$ \\
\hline NS1 & 475 & 0 & 80 & $27.7 \pm 4.1$ \\
\hline NS1 & 0 & 570 & 80 & $10.1 \pm 6.1$ \\
\hline NS2 & 475 & 0 & 80 & $37.5 \pm 2.5$ \\
\hline NS2 & 0 & 570 & 80 & $33.9 \pm 2.8$ \\
\hline $\mathrm{NS} 1+\mathrm{NS} 2$ & 475 & 0 & 80 & $38.4 \pm 0.9$ \\
\hline $\mathrm{NS} 1+\mathrm{NS} 2$ & 0 & 570 & 80 & $30.2 \pm 0.5$ \\
\hline Average $\pm S D$ & & & & $29.0 \pm 12.9$ \\
\hline
\end{tabular}

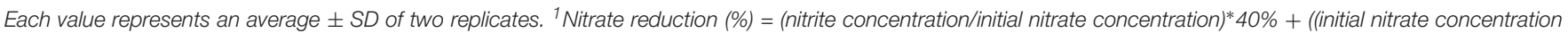
- residual nitrate concentration - nitrite concentration)/initial nitrate concentration)*100.

TABLE 3 | Summary of oil production from high pressure columns.

\begin{tabular}{|c|c|c|c|c|c|}
\hline Column & ROIP/PV ${ }^{1}$ & Substrates $^{2}$ & ABO-NRB ${ }^{3}$ inoculum & $\begin{array}{c}\text { ABO-NRB inoculum } \\
\left(\mathrm{OD}_{600}\right)\end{array}$ & $\begin{array}{l}\text { Oil produced (\% } \\
{\text { ROIP })^{4}}^{4}\end{array}$ \\
\hline 1,2 & $0.53 \pm 0.02$ & T & None & 0 & $2.5 \pm 0.1$ \\
\hline 5,6 & $0.39 \pm 0.01$ & EN & B_EN & $N D^{5}$ & $16.0 \pm 1.9$ \\
\hline 7 & 0.58 & $\mathrm{E}$ & C_EN (HMN) & 0.090 & 6.9 \\
\hline 8 & 0.62 & E & C_EN (HMN) & 0.092 & 5.5 \\
\hline 10 & 0.43 & T & C_TN (HMN) & 1.769 & 14.2 \\
\hline 11 & 0.60 & EN & C_EN (HMN) & 0.096 & 9.4 \\
\hline 12 & 0.54 & EN & C_EN (HMN) & 0.105 & 9.2 \\
\hline 13 & 0.47 & $\mathrm{TN}$ & C_TN (HMN) & 0.634 & 16.0 \\
\hline 14 & 0.42 & $\mathrm{TN}$ & C_TN (HMN) & 1.238 & 21.9 \\
\hline $15-17$ & $0.48 \pm 0.03$ & $\mathrm{TN}$ & NS1 & 0.281 & $10.5 \pm 4.5$ \\
\hline
\end{tabular}

These contained approximately 0.5 PV of heavy MHGC oil and 0.5 PV of aqueous phase. Ethylbenzene (E) or toluene (T) were added to the oil phase, whereas nitrate $(N)$ and ABO-NRB inoculum were injected with the aqueous phase, as indicated. Following 2.5 weeks of incubation flow was resumed and oil production was measured. Additional information is provided in Supplementary Table S6. ${ }^{1} R O I P(m L)=P V(m L)$ - produced oil $(\mathrm{mL}) .{ }^{2}$ Substrates were (E) $9.5 \mathrm{mM}$ of ethylbenzene in the oil phase, (T) $11.2 \mathrm{mM}$ toluene in the oil phase, and/or (N) $80 \mathrm{mM}$ nitrate in the aqueous phase of the columns. ${ }^{3}$ Inocula as in Table 1 and Figures $1,3 .{ }^{4}(\%)$ ROIP $=[O i l$ produced $(m L) / R O I P(m L)]^{*} 100 .{ }^{5} \mathrm{ND}$, not determined. 


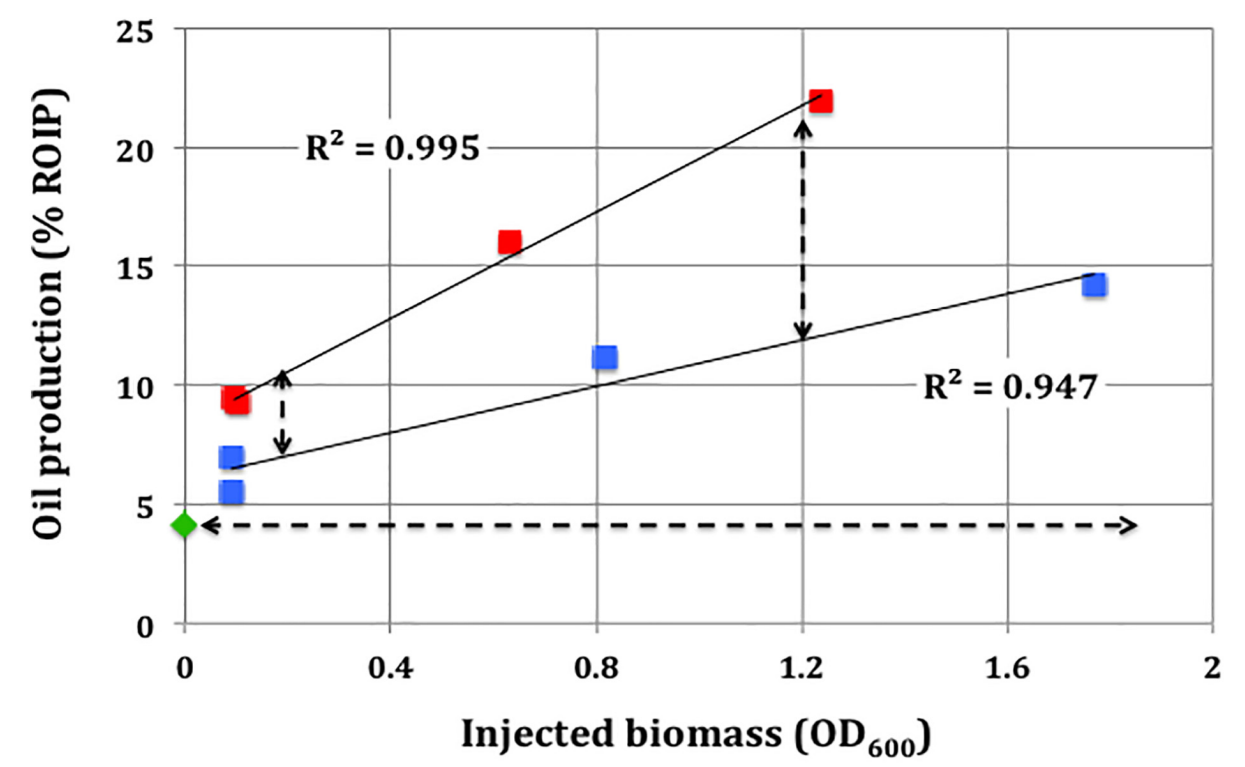

FIGURE 5 | Oil production from high pressure columns as a function of injected biomass concentration (OD 600$)$. Oil production (\% ROIP) from columns incubated with injected biomass without nitrate $(\square)$ and with $80 \mathrm{mM}$ nitrate $(\square)$ is shown. The diamond $(\checkmark)$ represents a negative control without added inoculum. The horizontal dotted line indicates oil production in the negative control. The vertical dotted lines indicate the increase in oil production due to the presence of nitrate.

to $7 \mathrm{mM}$ of ethylbenzene or toluene remained in the oil produced after incubation.

\section{Oil Production Using ABO-NRB Isolates}

Isolates NS1 and NS2 were grown in batch cultures in medium with $10 \mathrm{mM}$ acetate and $10 \mathrm{mM}$ nitrate. The grown cultures were centrifuged and the cells were resuspended either separately or together in CSBK medium with $80 \mathrm{mM}$ nitrate. High pressure columns 15 to 23 , containing residual heavy oil with $11.2 \mathrm{mM}$ of toluene, were injected with resuspended cultures, which had an $\mathrm{OD}_{600}$ of $0.258 \pm 0.020$. Following incubation and flooding with CSBK medium, these gave similar oil production. Columns inoculated with Thauera sp. NS1, Pseudomonas sp. NS2 or with both strains produced $10.5 \pm 4.5,7.3 \pm 1.9$, or $10.3 \pm 5.3 \%$ ROIP, respectively (Table 3 ). The average nitrate reduction observed in the aqueous phase of the effluents from these columns was $56.6 \pm 8.9 \%$ (Table 3: $N=9$ ). Oil production calculated based on equation 2 obtained for continuous culture ABO-NRB consortia for an $\mathrm{OD}_{600}=0.258$ is $11.2 \%$ of ROIP. The values obtained for pure culture isolates thus appear slightly lower and these do not offer an MEOR advantage compared to continuous cultures.

\section{DISCUSSION}

Microbially enhanced oil recovery often involves injection of (i) cheap carbohydrate (e.g., molasses) as a fermentation substrate, (ii) microbes that catalyze the desired fermentation outcome, (iii) limiting nutrients (e.g., phosphate) and (iv) an electron acceptor like nitrate. Fermentation of injected carbohydrate can yield organic acids, alcohols, gasses, biosurfactants, biomass and associated polymers such as exopolysaccharide (EPS) (Sen, 2008;
Youssef et al., 2009; Siegert et al., 2013), which contribute to MEOR in various ways. For instance, Youssef et al. (2007) showed that injection of two pre-cultured, lipopolypeptide biosurfactant-producing Bacillus strains, together with glucose, nitrate and salts increased oil production. The production of this lipopolypeptide biosurfactant in the oil-bearing subsurface, decreasing the oil-water interfacial tension, was demonstrated and was held responsible for the production of additional oil.

Production of biomass and associated EPS or other polymers can contribute to the plugging of high permeability zones in bioreactors or reservoirs, which is another suggested mechanism for MEOR. Because injected carbohydrate, nutrients, nitrate and microbial inoculum move primarily into high permeability zones, these will be blocked preferentially by microbial growth and associated polymer production (Youssef et al., 2009). Formation of EPS or other biopolymers augments the volume of the biomass. e.g., high density bacterial biomass occupies only about $0.4 \%$ of the volume of the aqueous phase (Supplementary Figure S5), but this can be enhanced considerably by biopolymer formation. Only polymer-producing bacteria have, therefore, been used successfully to stimulate oil recovery from sandpacks, carbonate cores and oil wells by flow diversion (Youssef et al., 2009).

Disadvantages of molasses-based MEOR is that the technology does not use the hydrocarbon substrate available downhole and that all substrates and fermenting microorganisms must be injected simultaneously. Reaction starts as soon as all component are mixed together and depth of penetration is thus dependent on injection flow rate versus reaction half life. In contrast, in hydrocarbon- and nitrate mediated MEOR oil hydrocarbons like toluene are used as substrates. However, because these are often in short supply in heavy oils, MEOR is improved by increasing the concentration of toluene in the oil by aqueous injection. Transfer 
of aqueous toluene to the oil phase increased its concentration by up to 10 -fold, depending on the aqueous toluene concentration used and the duration of the injection (Gassara et al., 2015). Use of toluene-enriched heavy oil and subsequent injection of nitrate and a toluene-oxidizing, nitrate-reducing enrichment culture gave production of $17.9 \pm 1.7 \%$ of ROIP (Gassara et al., 2015), whereas in the absence of inoculum and toluene and/or nitrate only $2.5 \pm 0.1 \%$ of ROIP was produced (Table 3). Gassara et al. (2015) found that a mixture of heptane and toluene was also effective and we have found in the present study that ethylbenzene is as effective as toluene. Note that we mention use of a heptane-toluene mixture in this sentence. Assuming adequate aqueous solubility the choice of the most appropriate low molecular weight hydrocarbon depends on availability, price and regulatory considerations.

Ethylbenzene and toluene are important electron donors for nitrate reduction (Rabus and Widdel, 1995; Chakraborty and Coates, 2004; Lambo et al., 2008; Agrawal et al., 2012; Suri et al., 2017). Toluene is anaerobically metabolized via fumarate addition while ethylbenzene oxidation involves dehydrogenation of the ethyl side chain as initial reactions under denitrifying conditions (Champion et al., 1999). Acetate and benzoate are intermediates of these metabolic pathways. Thauera and Pseudomonas were the top two taxa in the batch and continuous cultures used here (Figure 2 and Supplementary Table S3). Thauera sp. NS1 and Pseudomonas sp. NS2, isolated in this study, were able to grow on acetate, benzoate, ethylbenzene and toluene under denitrifying conditions (Figure 4). Thauera is a genus of well-studied denitrifying species, which can also use phenylacetate, indole, p-cresol, phenol and other electron donors (Spormann and Widdel, 2000; Mechichi et al., 2002; Fida et al., 2016). Isolate Thauera sp. NS1, had 99.0\% $16 \mathrm{~S}$ rRNA gene sequence similarity to Thauera aromatica strain S100, which uses benzoate but not toluene or ethylbenzene (Tschech and Fuchs, 1987; Mechichi et al., 2002). Our isolate Thauera sp. NS1 uses acetate, benzoate, toluene and ethylbenzene for nitrate reduction (Figure 4). Isolate Pseudomonas sp. NS2 also uses acetate, benzoate, toluene and ethylbenzene for nitrate reduction (Figure 4) and had $99.0 \%$ similarity to Pseudomonas stutzeri strain NBRC 12695. P. stutzeri strains use volatile fatty acids (VFA, which are acetate, propionate and butyrate), as well as aromatic compounds like benzoate, toluene, cresols and naphthalenes (Rijn et al., 1996; Arenghi et al., 1999; Lalucat et al., 2006).

Denitrifying ABO-NRB, such as Thauera sp. NS1 and Pseudomonas sp. NS2, can contribute to MEOR through production of $\mathrm{N}_{2}$ and $\mathrm{CO}_{2}$ gasses (Supplementary Table S5), which can push oil and water from porous media. The volume of gas formed depends on pressure and temperature, e.g., at 1 atm and $25^{\circ} \mathrm{C}$ a mole of gas occupies $25 \mathrm{~L}$, whereas at 27.2 atm, as used in our experiments, this is only $0.9 \mathrm{~L}$. Injection of these gasses at very high pressures $\left(10^{2}-10^{3} \mathrm{~atm}\right)$ increases their concentration in oil sufficiently to cause viscosity reduction, which is an established method of improving oil production (Holm and Josendal, 1974; Khatib and Earlougher, 1981; Hudgins et al., 1990; Ghasemi and Shadizadeh, 2011). A pressure of 27.2 atm is thus too high to produce oil by gas production, whereas it is too low to cause gas-mediated viscosity reduction. Thus, the possibility that gas production contributed to oil production from our high pressure columns is small.

Injection of low $\left(\mathrm{OD}_{600}=0.090\right)$ to high $\left(\mathrm{OD}_{600}=1.769\right)$ ABO-NRB biomass concentrations into the columns (Table 3) indicated that oil production increased with the injected biomass concentration both in the absence and presence of nitrate (Figure 5). Thauera has previously been found to attach to oil (Kryachko et al., 2012), whereas Pseudomonas can attach to hydrocarbon by increasing its cell surface hydrophobicity (Zhang and Miller, 1994; Beal and Betts, 2000; Obuweke et al., 2008; Fernandez et al., 2019). Theoretical calculations, indicated in the text with Supplementary Figure S5, indicate that attachment of ABO-NRB cells $\left(1.3 \times 10^{9}\right.$ cells $\left./ \mathrm{cm}^{3}\right)$ to the oil phase can emulsify $1.6 \mathrm{~cm}^{3}$ of oil per $17.5 \mathrm{~cm}^{3}$ of the aqueous pore volume that was present in our columns (Table 3), when oil emulsion droplets of an average diameter of $250 \mu \mathrm{m}$ are formed. Although there are quite a few assumptions in these calculations it is interesting that emulsification can in principle produce the $2 \mathrm{~cm}^{3}$ of oil per $17.5 \mathrm{~cm}^{3}$ of aqueous volume seen in our experiments (Table 3). In reality, the contribution of emulsification is likely less, whereas the largest emulsion droplets may also contribute to through flow diversion. Injection of similar sand-packed columns with sufficient aqueous molasses, glucose or acetate to reduce $80 \mathrm{mM}$ of injected nitrate gave production of 14 , 11 and $18 \%$ of ROIP, respectively, under low pressure (1 atm) conditions (Gassara et al., 2017). Hence, hydrocarbon- and nitrate-mediated MEOR is similarly effective as carbohydrateand nitrate-mediated MEOR, which likely involves a different mechanism that does not involve attachment of cells to oil, e.g., through biosurfactants (Okpokwasili and Ibiene, 2006; Youssef et al., 2007; Safdel et al., 2017).

Oil production using pure isolates Thauera sp. NS1 and Pseudomonas sp. NS2 was somewhat lower than that using ABO-NRB batch and continuous cultures (Table 3), indicating that other taxa in the microbial community also promoted hydrocarbon- and nitrate-mediated MEOR.

In summary, these results indicate that stimulating the microbial communities that are naturally present in low temperature, heavy oil-containing fields by injection of low molecular weight, water-soluble hydrocarbons followed by injection of nitrate and nutrients (e.g., phosphate) is the most promising strategy. Injection of strains with particular metabolic characteristics, as in many applications of carbohydrate- and nitrate-mediated MEOR (Youssef et al., 2007, 2009) is not needed. The injected low molecular weight hydrocarbon is transferred to the oil phase. Attachment to oil and growth of oil-attached bacteria on this low molecular weight hydrocarbon and aqueous nitrate leads to emulsification. The calculations presented indicate that this mechanism can account for the production of residual oil in place observed in this study.

\section{DATA AVAILABILITY}

The datasets generated for this study can be found in Genbank and NCBI, MK085068 and MK085069; SAMN10280305 to SAMN10280325. 


\section{AUTHOR CONTRIBUTIONS}

NS planned and conducted the experiments, collected, analyzed, and interpreted the data, drafted and revised the manuscript. FG helped in conducting the initial experiments. PS helped in setting and operating the high-pressure columns. GV supervised the work through ideas and discussions, critically revised and approved the manuscript to be published.

\section{FUNDING}

This work was supported by an NSERC Industrial Research Chair Award to GV and the industry sponsors that included BP America Production Co., Baker Hughes Canada, Computer Modeling Group Limited, ConocoPhillips Company, Dow Microbial Control, Enbridge, Enerplus Corporation,

\section{REFERENCES}

Agrawal, A., Park, H. S., Nathoo, S., Gieg, L. M., Jack, T. R., Miner, K., et al. (2012). Toluene depletion in produced oil contributes to souring control in a field subjected to nitrate injection. Environ. Sci. Technol. 46, 1285-1292. doi: 10.1021/es203748b

Allen, M. S., Welch, K. T., Prebyl, B. S., Baker, D. C., Meyers, A. J., and Sayler, G. S. (2004). Analysis and glycosyl composition of the exopolysaccharide isolated from the floc-forming wastewater bacterium Thauera sp. MZ1T. Environ. Microbiol. 6, 780-790. doi: 10.1111/j.1462-2920.2004.00615.x

An, D., Caffrey, S. M., Soh, J., and Agrawal, A. (2013). Metagenomics of hydrocarbon resource environments indicates aerobic taxa and genes to be unexpectedly common. Environ. Sci. Technol. 47, 10708-10717. doi: 10.1021/ es4020184

Arenghi, F. L. G., Pinti, M., Galli, E., and Barbieri, P. (1999). Identification of the Pseudomonas stutzeri OX1 toluene-o-xylene monooxygenase regulatory gene (touR) and of its cognate promoter. Appl. Environ. Microbiol. 65, 4057-4063.

Beal, R., and Betts, W. B. (2000). Role of rhamnolipid biosurfactants in the uptake and mineralization of hexadecane in Pseudomonas aeruginosa. J. Appl. Microbiol. 89, 158-168. doi: 10.1046/j.1365-2672.2000.01104.x

Chakraborty, R., and Coates, J. D. (2004). Anaerobic degradation of monoaromatic hydrocarbons. Appl. Microbiol. Biotechnol. 64, 437-446. doi: 10.1007/s00253003-1526-x

Champion, K. M., Zengler, K., and Rabus, R. (1999). Anaerobic degradation of ethylbenzene and toluene in denitrifying strain EbN1 proceeds via independent substrate-induced pathways. J. Molec. Microbiol. Biotechnol. 1, 157-164.

Chen, C., Shen, Y., An, D., and Voordouw, G. (2017). Use of acetate, propionate, and butyrate for reduction of nitrate and sulfate and methanogenesis in microcosms and bioreactors simulating an oil reservoir. Appl. Environ. Microbiol. 83, e2983-e2916. doi: 10.1128/AEM.02983-16

Dong, X., Kleiner, M., Sharp, C. E., Thorson, E., Li, C., Liu, D., et al. (2017). Fast and simple analysis of MiSeq amplicon sequencing data with MetaAmp. Front. Microbiol. 8:1461. doi: 10.3389/fmicb.2017.01461

Felsenstein, J. (1985). Confidence limits on phylogenies: an approach using the bootstrap. Evolution 39, 783-791. doi: 10.1111/j.1558-5646.1985.tb00420.x

Fernandez, V. I., Stocker, R., and Juarez, G. (2019). "Modeling the impact of dilution on the microbial degradation time of dispersed oil in marine environments," in Oilfield Microbiology, eds C. B. Whitby and T. L. Skovhus (Florida, US: CRC press).

Fida, T. T., Chen, C., Okpala, G., and Voordouw, G. (2016). Implications of limited thermophilicity of nitrite reduction for control of sulfide. Appl. Environ. Microbiol. 82, 4190-4199. doi: 10.1128/AEM.00599-16

Frank, J. A., Reich, C. I., Sharma, S., Weisbaum, J. S., Wilson, B. A., and Olsen, G. J. (2008). Critical evaluation of two primers commonly used for amplification of bacterial 16S rRNA genes. Appl. Environ. Microbiol. 74, 2461-2470. doi: 10.1128/AEM.02272-07
Intertek, Oil Search (PNG) Limited, Shell Global Solutions International, Suncor Energy Inc., and Yara Norge AS and Alberta Innovates.

\section{ACKNOWLEDGMENTS}

We are thankful to Dr. Rhonda Clark and Yin Shen for administrative support. We are also thankful to Johanna Voordouw for technical support.

\section{SUPPLEMENTARY MATERIAL}

The Supplementary Material for this article can be found online at: https://www.frontiersin.org/articles/10.3389/fmicb. 2019.01243/full\#supplementary-material

Gassara, F., Suri, N., Stanislav, P., and Voordouw, G. (2015). Microbially enhanced oil recovery by sequential injection of light hydrocarbon and nitrate in lowand high-pressure bioreactors. Environ. Sci. Technol. 49, 12594-12601. doi: 10.1021/acs.est.5b03879

Gassara, F., Suri, N., and Voordouw, G. (2017). Nitrate-mediated microbially enhanced oil recovery (N-MEOR) from model upflow bioreactors. J. Hazard. Mat. 324, 94-99. doi: 10.1016/j.jhazmat.2015.12.039

Ghasemi, M., and Shadizadeh, S. R. (2011). Experimental comparison of nitrogen and carbon dioxide oil displacement in carbonate cores. Pet. Sci. Technol. 29, 2560-2567. doi: 10.1080/10916461003716632

Hall, T. A. (1999). BioEdit : a user friendly biological sequence alignmnet editor and analysis program for windows 95/98/NT. Nucl. Acids. Symp. Ser. 41, 95-98.

Holm, L. W., and Josendal, V. A. (1974). Mechanisms of oil displacement by carbon dioxide. J. Pet. Technol. 26, 427-438. doi: 10.1016/j.mri.2016.12.003

Hudgins, A. D., Llave Fellclano, M., and Chung Frank, T. H. (1990). Nitrogen miscible displacement of light crude oil: a laboratory study. SPE Reservoir. Eng. 5, 100-106. doi: 10.2118/17372-pa

Khatib, A. K., and Earlougher, R. C. (1981). CO2 injection as an immiscible application for enhanced recovery in heavy oil reservoirs. in Proceedings of the California Regional Meeting, Bakersfield, CA, 461-471.

Kimura, M. (1980). A simple method for estimating evolutionary rates of base substitutions through comparative studies of nucleotide sequences. J. Mol. Evol. 16, 111-120. doi: 10.1007/bf01731581

Kryachko, Y., Dong, X., Sensen, C. W., and Voordouw, G. (2012). Compositions of microbial communities associated with oil and water in a mesothermic oil field. Antonie van Leeuwenhoek. 101, 493-506. doi: 10.1007/s10482-011-9658-y

Kryachko, Y., and Voordouw, G. (2014). Microbially enhanced oil recovery from miniature model columns through stimulation of indigenous microflora with nitrate. Int. Biodeterior. Biodegrad. 96, 135-143. doi: 10.1016/j.ibiod.2014. 08.013

Kumar, S., Stecher, G., and Tamura, K. (2016). MEGA7: molecular evolutionary genetics analysis version 7.0 for bigger datasets. Mol. Biol. Evol. 33, 1870-1874. doi: 10.1093/molbev/msw054

Lalucat, J., Bennasar, A., Bosch, R., Garci'a-Valde's, E., and Pallleroni, N. J. (2006). Biology of Pseudomonas stutzeri. Microbiol. Mol. Bio. Rev. 70, 510-547. doi: 10.1128/MMBR.00047-05

Lambo, A. J., Noke, K. I., Larter, S. R., and Voordouw, G. (2008). Competitive, microbially mediated reduction of nitrate with sulphide and aromatic oil components in a low temperature. West. Can. Oil Reserv. Environ. Sci. Technol. 42, 8941-8946. doi: 10.1021/es801832s

Larkin, M. A., Blackshields, G., Brown, N. P., Chenna, R., McGettigan, P. A., McWilliam, H., et al. (2007). Clustal W and Clustal X version 2.0. Bioinformatics 23, 2947-2948. doi: 10.1093/bioinformatics/btm404

Mechichi, T., Stackebrandt, E., Gad'on, N., and Fuchs, G. (2002). Phylogenetic and metabolic diversity of bacteria degrading aromatic compounds under denitrifying conditions, and description of Thauera phenylacetica sp. nov., 
Thauera aminoaromatica sp. nov., and Azoarcus buckelii sp. nov. Arch. Microbiol 178, 26-35. doi: 10.1007/s00203-002-0422-6

Menon, P., and Voordouw, G. (2018). Impact of light oil toxicity on sulfide production by acetate-oxidizing, sulfate-reducing bacteria. Int. Biodeterior. Biodegrad. 126, 208-215. doi: 10.1016/j.ibiod.2016.11.021

Nakagawa, Y., Muramatsu, Y., Miyashita, M., Sugimoto, M., Yoshino, M., and Kamakura, Y. (2011). direct submission. Available at: https://www.ncbi.nlm. nih.gov/nuccore/AB681922.1 (accessed November 10, 2011).

Obuweke, C. O., Al-Jadi, Z. K., and Al-Saleh, E. S. (2008). Insight into heterogeneity in cell-surface hydrophobicity and ability to degrade hydrocarbons among cells of two hydrocarbon-degrading bacterial populations. Can. J. Microbiol. 53, 252-260. doi: 10.1139/W0 6-115

Okpokwasili, G., and Ibiene, A. (2006). Enhancement of recovery of residual oil using a biosurfactant slug. Afr. J. Biotechnol. 5:453.

Rabus, R. (2005). Functional genomics of an anaerobic aromatic-degrading denitrifying bacterium, strain EbN1. Appl. Microbiol. Biotechnol. 68, 580-587. doi: 10.1007/s00253-005-0030-x

Rabus, R., and Widdel, F. (1995). Anaerobic degradation of ethylbenzene and other aromatic hydrocarbons by new denitrifying bacteria. Arch. Microbiol. 163, 96-103. doi: $10.1007 / \mathrm{s} 002030050177$

Rabus, R., Wilkes, H., Schramm, A., Harms, G., Behrends, A., Amann, R., et al. (1999). Anaerobic utilization of alkylbenzenes and n-alkanes from crude oil in an enrichment culture of denitrifying bacteria affiliating with the $\beta$-subclass of Proteobacteria. Environ. Microbiol. 1, 145-157. doi: 10.1046/j.1462-2920.1999. 00014.x

Rijn, J. V., Tal, Y., and Barak, Y. (1996). Influence of volatile fatty acids on nitrite accumulation by a Pseudomonas stutzeri strain isolated from a denitrifying fluidized bed reactor. Appl. Environ. Microbiol. 62, 2615-2620.

Safdel, M., Anbaz, M. A., Daryasafar, A., and Jamialahmadi, M. (2017). Microbial enhanced oil recovery, a critical review on worldwide implemented field trials in different countries. Ren. Sust. Ener. Rev. 74, 159-172. doi: 10.1016/j.rser.2017. 02.045

Saitou, N., and Nei, M. (1987). The neighbor-joining method: a new method for reconstructing phylogenetic trees. Mol. Biol. Evol. 4, 406-425. doi: 10.1093/ oxfordjournals.molbev.a040454

Schmid, J., Sieber, V., and Rehm, B. (2015). Bacterial exopolysaccharides: biosynthesis pathways and engineering strategies. Front. Microbiol. 6:496. doi: $10.3389 /$ fmicb. 2015.00496

Sen, R. (2008). Biotechnology in petroleum recovery: the microbial EOR. Prog. Ener. Combust. Sci. 34, 714-724. doi: 10.1016/j.pecs.2008. 05.001
Shen, Y., Agrawal, A., Suri, N. K., An, D., Voordouw, J. K., Clark, R. G., et al. (2018). Control of microbial sulfide production by limiting sulfate dispersal in a water-injected oil field. J. Biotech. 266, 14-19. doi: 10.1016/j.jbiotec.2017.11.016

Siegert, M., Sitte, J., Galushko, A., and Kruger, M. (2013). Starting Up Microbial Enhanced Oil Recovery. Adv. Biochem. Eng. Biotechnol. 142, 1-94. doi: 10.1007/ 10_2013_256

Spormann, A. M., and Widdel, F. (2000). Metabolism of alkylbenzenes, alkanes, and other hydrocarbons in anaerobic bacteria. Biodegrad 11, 85-105. doi: 10. 1023/A:1011122631799

Suri, N., Voordouw, J., and Voordouw, G. (2017). The effectiveness of nitratemediated control of the oil field sulfur cycle depends on the toluene content of the oil. Front. Microbiol. 8:956. doi: 10.3389/fmicb.2017.00956

Tschech, A., and Fuchs, G. (1987). Anaerobic degradation of phenol by pure culture of newly isolated denitrifying Pseudomonads. Arch. Microbiol. 148, 213-217. doi: $10.1007 /$ bf00414814

Voordouw, G., Grigoryan, A. A., Lambo, A., Lin, S., Park, H. S., Jack, T. R., et al. (2009). Sulfide remediation by pulsed injection of nitrate into a low temperature Canadian heavy oil reservoir. Environ. Sci. Technol. 43, 9512-9518. doi: $10.1021 /$ es902211j

Weelink, S. A. B., van Eekert, M. H. A., and Stams, A. J. M. (2010). Degradation of BTEX by anaerobic bacteria: physiology and application. Rev. Environ. Sci. Biotechnol. 9, 359-385. doi: 10.1007/s11157-010-9219-2

Youssef, N., Elshahed, M. S., and McInerney, M. J. (2009). Microbial processes in oil fields: culprits, problems and opportunities. Adv. Appl. Microbiol. 66, 141-251. doi: 10.1016/S0065-2164(08)00806-X

Youssef, N., Simpson, D. R., Duncan, K. E., McInerney, M. J., Folmsbee, M., Fincher, T., et al. (2007). In situ biosurfactant production by Bacillus strains injected into a limestone petroleum reservoir. Appl. Environ. Microbiol. 73, 1239-1247. doi: 10.1128/aem.02264-06

Zhang, Y., and Miller, R. M. (1994). Effect of a Pseudomonas rhamnolipid biosurfactant on cell hydrophobicity and biodegradation of octadecane. Appl. Environ. Microbiol. 60, 2101-2106.

Conflict of Interest Statement: The authors declare that the research was conducted in the absence of any commercial or financial relationships that could be construed as a potential conflict of interest.

Copyright (c) 2019 Suri, Gassara, Stanislav and Voordouw. This is an open-access article distributed under the terms of the Creative Commons Attribution License (CC BY). The use, distribution or reproduction in other forums is permitted, provided the original author(s) and the copyright owner(s) are credited and that the original publication in this journal is cited, in accordance with accepted academic practice. No use, distribution or reproduction is permitted which does not comply with these terms. 